\title{
Age-related fall risk characteristics in Japanese community-dwelling elderly ${ }^{*}$
}

\author{
Susumu Sato ${ }^{1 \#}$, Shinichi Demura ${ }^{2}$, Toshiro Sato ${ }^{3}$, Kenji Takahashi $^{4}$ \\ ${ }^{1}$ Kanazawa Institute of Technology, Nonoichi, Japan \\ ${ }^{2}$ Graduate School of Natural Science and Technology, Kanazawa University, Kanazawa, Japan \\ ${ }^{3}$ Niigata University of Health and Welfare, Niigata, Japan \\ ${ }^{4}$ Teikyo Heisei University, Ichihara, Japan \\ Email: "sssato@neptune.kanazawa-it.ac.jp
}

Received 1 April 2013; revised 2 May 2013; accepted 9 May 2013

Copyright (C) 2013 Susumu Sato et al. This is an open access article distributed under the Creative Commons Attribution License, which permits unrestricted use, distribution, and reproduction in any medium, provided the original work is properly cited.

\section{ABSTRACT}

This study aimed to determine age-related fall risk characteristics among 2324 Japanese communitydwelling elderly through comparisons between youngold and old-old populations. Fall risk characteristics associated with "physical function", "disease and physical symptom", "behavior and character", and "environment" were evaluated, and whether each individual has a high-risk symptom for each risk factor was assessed. The frequencies of individuals for all 16 risk types, which were determined by a combination of the four risk factors, were calculated. The prevalence of each risk type and the incidence of falling in each risk type were calculated within the young-old and old-old groups, and significant differences between these percentages were examined using the chi-square test. The prevalence of the no high-risk symptom group was significantly lower in the old-old group (17.0\%) than in the young-old group (45.2\%). Although there was no significant difference in the prevalence of the single high-risk symptom group, the prevalence of the two or more high-risk symptom groups was significantly higher in the old-old group. The incidence of fall among the elderly with high-risk symptoms did not change with age, although the incidence of fall with no high-risk symptom increased in the old-old group. Furthermore, high prevalence was observed in risk types with high-risk symptoms for "physical function" and "behavior and character", particularly in the symptoms of gait, going up and down stairs, and fear of falling. These age-related differences are interesting and meaningful.

${ }^{*}$ Competing inter: We declare that we have no competing interests.

${ }^{*}$ Corresponding author.
Keywords: Prevalence of High-Risk Symptom; Incidence of Fall; Fall Risk Type

\section{INTRODUCTION}

The Japanese average life expectancy is increasing, already reaching 79.64 years for men and 86.39 years for women in 2011 [1]. According to the "World Health Statistics," published by the World Health Organization, the Japanese healthy life expectancy is 73 years for men and 78 years for women, and Japan has the highest level of longevity in the world [2,3]. In Japan's increasingly aging society, closing the gap between life expectancy and healthy life expectancy is important for the older individuals and the Japanese society, and it is important to realize the importance of successful aging. In Japan, with a long life expectancy, an important concern in health promotion for successful aging is prevention of becoming in a condition of need for long-term care (prevention of dysfunction). Prevention of the metabolic syndrome is the major concern in health promotion until approximately middle-age. However, health promotion for the elderly, particularly the old-old elderly, should focus on dysfunction or disuse atrophy. The Japanese Orthopaedic Association has proposed the concept of a "loco-motive syndrome," which refers to conditions under which the elderly have been receiving care services, or high-risk conditions under which they may soon require care services, because of problems in locomotive organs $[4,5]$. Countermeasure for the locomotive syndrome is one of the major concerns in health promotion for the elderly.

"Fall" is an event which creates acute dysfunction or disorder in the locomotive organs of elderly individuals, and primary preventive long-term care for fall is impor- 
tant. Fall risk assessment is one of the primary preventions of fall, and several assessments have been examined, including the performance test-based fall risk assessments, which evaluate fall-related physical fitness and are used to screen the fall risk level, or questionnaire-based fall risk assessments, which evaluate fall risk comprehensively, including various internal and external fall risk factors [6-10]. Various internal and external factors are comprehensively related to the development of fall. Elderly people tend to have multiple fall risks or fall more often, and their fall risk combinations are unique to each individual [11].

We examined a questionnaire-based fall risk assessment for the community-dwelling elderly, and propose a fall risk profile assessment based on four risk factors: physical function, disease and physical symptom, behavior and character, and environment $[12,13]$. In this examination, a high-risk symptom for each risk factor is screened, and a risk type is determined for each individual. Furthermore, we gathered these individual assessment outcomes and calculated the prevalence of each risk type or the incidence ratio of fall. In this examination, we clarified some fall risk characteristics of the population by classifying the community-dwelling elderly into three groups: the elderly without a high-risk symptom for any fall risk factor, the elderly with only one high-risk symptom for any risk factor, and the elderly with two or more high-risk symptoms. The prevalence of these three groups was approximately 30\% each, and the incidence of fall of the elderly individuals increased with the increase in high-risk symptoms [13].

These population characteristics will be expected to change with age; however, these age-related characteristics have not been sufficiently examined. In Japan, where the average life expectancy exceeds 80 years, countermeasures to prevent the need for medical care in the oldold population is an important issue, and fall risk characteristics of this population have become useful information. This study aimed to determine the fall risk characteristics among 2000 or more community-dwelling elderly individuals and to clarify the age-related differences in these characteristics between the young-old and oldold elderly.

\section{METHODS}

\subsection{Participants and Data Collection}

The participants in this study were healthy, communitydwelling elderly individuals aged 60 years and more, living in the Akita, Kanagawa, Ishikawa, Fukui, Nagano, Gifu, Aichi, Tottori, and Fukuoka prefectures in Japan. Among these, 2324 elderly subjects $(70.3 \pm 7.1$ years $)$ missing less than $10 \%$ of the data were used for data analysis in this study. This participant pool comprised
426 young-old males (67.9 \pm 4.2 years), 1073 young-old females (67.9 \pm 4.2 years), 235 old-old males (79.2 \pm 3.7 years), and 590 old-old females (79.8 \pm 4.0 years). This study was approved by the Ethics Committee on Human Experimentation of Faculty of Education, Kanazawa University. An explanation of this study was provided throughout using written materials, and informed consent was obtained in writing from each participant.

\subsection{Fall Risk Assessment}

To assess fall risk characteristics in the communitydwelling elderly, this study used Demura's fall risk assessment chart (DFRA), which is composed of 50 fall risk assessment items representing five risk factors: "potential for falling”, "physical function”, “disease and physical symptom”, "environment”, and "behavior and character" [14].

"Potential for falling" is a factor concerned with the occurrence of precursors of falls and is assessed by the following three questions: "Have you often stumbled?", "In the past year, have you felt like you might fall down?" and "Have you ever been told that you look like you might fall down?" "Physical function" was assessed using 22 items selected from eight domains (muscular strength, lower limb strength, balancing ability, walking ability, going up and down stairs, changing and holding posture, upper limb function, and gait). "Disease and physical symptom” was assessed using 13 items selected from six domains (dizziness and instances of blackout, medication, sight/hearing and cognitive disorder, cerebral vascular disease, arthritic and bone disease, and circulatory disease). "Environment" was assessed using four items selected from two domains (surrounding environment, and clothing). "Behavior and character" was assessed using eight items selected from four domains (inactivity, frequent urination, fear of falling, and risky behavior).

All the responses were recorded on a dichotomous scale (yes or no), with one point being assigned to each response falling into the "high risk" category. A risk factor score was calculated by adding the scores of the structural items of each risk factor.

In DFRA, a comprehensive fall risk level is evaluated using the "potential for falling" score, and the cut-off point is set at a single point (screening assessment) $[13,15]$. Furthermore, a personal fall risk profile is determined using the other four risk factor scores (physical function, disease and physical symptom, environment, and behavior and character).

\subsection{Determination of "High-Risk Symptom” for Each Risk Factor}

As mentioned above, in DFRA, there is a criterion for 
screening a person at a high risk of falling. To clarify the characteristics of fall risk among the community-dwelling elderly, this study attempted to determine the presence or absence of a "high-risk symptom" for each risk factor (physical function, disease and physical symptom, behavior and character, and environment) by applying the criterion for screening a person at a high risk of falling.

In DFRA, the prevalence of fall at each point for each risk factor score-which is the percentage of the elderly who have fallen in the last 12 months within all the elderly receiving the same score-was calculated to assess the fall risk profile in the previous study. For instance, in the "behavior and character" score, the prevalence of fall for each point was $6 \%$ (0 points), 10\% (1 points), 14\% (2 points), 25\% (3 points), 32\% (4 points), and 43\% (5 and 6 points).

The fall prevalence of the cut-off point for screening a high-risk person (potential for fall score $=1$ ) was $28 \%$. This study interpreted each risk factor score showing a prevalence of fall equivalent to or greater than " $28 \%$ " as the score equivalent to the cut-off point in the potential for fall score and used this score as a cut-off point for screening a high-risk symptom for each risk factor or its components. In case of the "behavior and character" factor, if a factor score exceeded 4 points, it was interpreted that the person has a "high-risk symptom" for the risk factor. The risk factor scores considered equivalent to the cut-off point in potential for the fall factor were as follows: physical function = 13 points; disease and physical symptom $=6$ points; behavior and character $=4$ points; environment $=4$ points. This study used this prevalence of fall as the criterion to determine the presence or absence of "high-risk symptoms".

\subsection{Statistics}

This study attempted to clarify population fall risk characteristics using the data regarding the presence or absence of high-risk symptoms for each risk factor. This study examined which fall risk types are commonly found among the community-dwelling elderly population and which differences in the prevalence of fall are observed among these fall risk types. Because this study used the four fall risk factors (physical function, disease and physical symptom, behavior and character, and environment), every conceivable combination obtained from the presence or absence of four risk factors form 16 types (Table 1).

In this study, raw data for each risk factor score for

Table 1. The prevalence of each risk type and its difference between the young-old and old-old age groups.

\begin{tabular}{|c|c|c|c|c|c|c|c|c|c|c|c|c|}
\hline \multirow[b]{2}{*}{ Risk types } & & \multicolumn{4}{|c|}{ Fall risk factors } & \multicolumn{3}{|c|}{ Young-old age group } & \multicolumn{3}{|c|}{ Old-old age group } & \multirow[b]{2}{*}{$\begin{array}{c}\text { Chi-square } \\
\text { values }\end{array}$} \\
\hline & & $\begin{array}{l}\text { Physical } \\
\text { function }\end{array}$ & $\begin{array}{c}\text { Disease and } \\
\text { physical } \\
\text { symptom }\end{array}$ & $\begin{array}{l}\text { Behavior } \\
\text { and } \\
\text { character }\end{array}$ & Environment & $\mathrm{n}$ & $\%$ & $\%{ }^{\#}$ & $\mathrm{n}$ & $\%$ & $\%^{\#}$ & \\
\hline \multirow[t]{2}{*}{$\begin{array}{c}\text { No high-risk } \\
\text { symptom group }\end{array}$} & Type 1 & $\mathrm{~N}$ & $\mathrm{~N}$ & $\mathrm{~N}$ & $\mathrm{~N}$ & 678 & 45.2 & & 140 & 17.0 & & $186.3^{*}$ \\
\hline & Type 2 & $\mathrm{P}$ & $\mathrm{N}$ & $\mathrm{N}$ & $\mathrm{N}$ & 226 & 15.1 & 47.2 & 232 & 28.1 & 81.1 & $57.2^{*}$ \\
\hline \multirow{3}{*}{$\begin{array}{l}\text { Only one high-risk } \\
\text { symptom groups }\end{array}$} & Type 3 & $\mathrm{~N}$ & $\mathrm{P}$ & $\mathrm{N}$ & $\mathrm{N}$ & 26 & 1.7 & 5.4 & 8 & 1.0 & 2.8 & 2.2 \\
\hline & Type 4 & $\mathrm{~N}$ & $\mathrm{~N}$ & $\mathrm{P}$ & $\mathrm{N}$ & 200 & 13.3 & 41.8 & 42 & 5.1 & 14.7 & $38.8^{*}$ \\
\hline & Type 5 & $\mathrm{~N}$ & $\mathrm{~N}$ & $\mathrm{~N}$ & $\mathrm{P}$ & 27 & 1.8 & 5.6 & 4 & 0.5 & 1.4 & $7.0^{*}$ \\
\hline \multirow{8}{*}{$\begin{array}{l}\text { Double high-risk } \\
\text { symptoms groups }\end{array}$} & & & & & Subtotal & 479 & 32.0 & 100.0 & 286 & 34.7 & 100.0 & 1.8 \\
\hline & Type 6 & $\mathrm{P}$ & $\mathrm{P}$ & $\mathrm{N}$ & $\mathrm{N}$ & 32 & 2.1 & 12.8 & 47 & 5.7 & 18.2 & $20.6^{*}$ \\
\hline & Type 7 & $\mathrm{P}$ & $\mathrm{N}$ & $\mathrm{P}$ & $\mathrm{N}$ & 162 & 10.8 & 64.8 & 188 & 22.8 & 72.9 & $59.7^{*}$ \\
\hline & Type 8 & $\mathrm{P}$ & $\mathrm{N}$ & $\mathrm{N}$ & $\mathrm{P}$ & 18 & 1.2 & 7.2 & 8 & 1.0 & 3.1 & 0.3 \\
\hline & Type 9 & $\mathrm{~N}$ & $\mathrm{P}$ & $\mathrm{P}$ & $\mathrm{N}$ & 15 & 1.0 & 6.0 & 5 & 0.6 & 1.9 & 1.0 \\
\hline & Type 10 & $\mathrm{~N}$ & $\mathrm{P}$ & $\mathrm{N}$ & $\mathrm{P}$ & 2 & 0.1 & 0.8 & 0 & 0.0 & 0.0 & 1.1 \\
\hline & Type 11 & $\mathrm{~N}$ & $\mathrm{~N}$ & $\mathrm{P}$ & $\mathrm{P}$ & 21 & 1.4 & 8.4 & 10 & 1.2 & 3.9 & 0.1 \\
\hline & & & & & Subtotal & 250 & 16.7 & 100.0 & 258 & 31.3 & 100.0 & $66.4^{*}$ \\
\hline \multirow{4}{*}{$\begin{array}{l}\text { Triple high-risk } \\
\text { symptoms groups }\end{array}$} & Type 12 & $\mathrm{P}$ & $\mathrm{P}$ & $\mathrm{P}$ & $\mathrm{N}$ & 54 & 3.6 & 63.5 & 108 & 13.1 & 85.0 & $73.9^{*}$ \\
\hline & Type 13 & $\mathrm{P}$ & $\mathrm{P}$ & $\mathrm{N}$ & $\mathrm{P}$ & 2 & 0.1 & 2.4 & 5 & 0.6 & 3.9 & $4.0^{*}$ \\
\hline & Type 14 & $\mathrm{P}$ & $\mathrm{N}$ & $\mathrm{P}$ & $\mathrm{P}$ & 25 & 1.7 & 29.4 & 13 & 1.6 & 10.2 & 0.0 \\
\hline & Type 15 & $\mathrm{~N}$ & $\mathrm{P}$ & $\mathrm{P}$ & $\mathrm{P}$ & 4 & 0.3 & 4.7 & 1 & 0.1 & 0.8 & 0.5 \\
\hline \multirow{3}{*}{$\begin{array}{l}\text { Quadruple high-risk } \\
\text { symptoms group }\end{array}$} & & & & & Subtotal & 85 & 5.7 & 100.0 & 127 & 15.4 & 100.0 & $60.7^{*}$ \\
\hline & Type 16 & $\mathrm{P}$ & $\mathrm{P}$ & $\mathrm{P}$ & $\mathrm{P}$ & 7 & 0.5 & & 14 & 1.7 & & $9.0^{*}$ \\
\hline & & & & & Total & 1499 & & & 825 & & & \\
\hline
\end{tabular}

P: positive presence of high-risk symptoms; N: negative absence of high-risk symptoms; ${ }^{*}: \mathrm{p}<0.05$; \% ${ }^{\sharp}$ : percentage within the subtotal. 
each individual were converted into the data for the presence or absence of high-risk symptoms for each fall risk factor, and the frequencies of individuals with highrisk symptoms were calculated for all the 16 fall risk types. Furthermore, the number of individuals experiencing a fall was counted for each risk type group, and the prevalence of fall was calculated.

These analyses were also organized according to the young-old and old-old groups, and significant differences in the prevalence of each risk type between the two age groups were calculated using the chi-square test. Significant level in this study was set at $\mathrm{p}$ values $<0.05$.

\section{RESULTS}

\subsection{Prevalence of Each Risk Type}

Table 1 shows the prevalence of each risk type. The prevalence of the elderly with no high-risk symptom (type 1) was significantly lower in the old-old group (17.0\%) than in the young-old group (45.2\%). Although there was no significant difference in the prevalence of the elderly with only one high-risk symptom between the young-old (32.0\%) and old-old (34.7\%) groups, the prevalence of elderly with two or more high-risk symptoms was significantly higher in the old-old group (double high-risk symptoms group: $16.7 \%$ vs 31.3\%; triple high-risk symptoms group: $5.7 \%$ vs $15.0 \%$; and quadruple high-risk symptoms group: $0.5 \%$ vs $1.7 \%$, respectively).

Nine of the 16 risk types showed significant differences in prevalence between the young-old and old-old age groups. Among the risk types with a single high-risk symptom (types 2-5), the percentage of the elderly subjects with a high-risk symptom for "physical function" (type 2) was significantly higher in the old-old group; however, the percentages of the elderly subjects with a high-risk symptom for "behavior and character" (type 4) and "environment" (type 5) were significantly lower in the old-old population. Among the risk types with two or more high-risk symptoms (types 6-16), the percentages of the elderly subjects having high-risk symptoms for "physical function" and "disease and physical symptom" (type 6); for "physical function" and "behavior and character" (type 7); for "physical function”, “disease and physical symptom", and "behavior and character" (type 12); and for "physical function", "disease and physical symptom”, and "environment” (type 13) were significantly higher in the old-old population.

Among the risk types, the prevalence of risk types with high-risk symptoms for either "physical function" or "behavior and character" (types 2, 4, 6, 7, 12 and 14) tended to be high, and this trend was found in both the age groups. However, the percentage of the elderly subjects with a high-risk symptom for "physical function" (type 2) nearly doubled from the young-old (47\%) to the old-old age group (81\%). In the final analysis, these observations suggest that problems regarding physical function increase in the old-old population.

\subsection{Incidence of Falling in Each Risk Type}

Table 2 shows the incidence of fall in each risk type. The total incidence of fall was significantly higher in the old-old group (17.1\%) than in the young-old group (12.3\%); however, there were no significant differences in any individual risk type.

The incidence of fall in the no high-risk symptom group was $7.2 \%$ in the young-old group and $11.4 \%$ in the old-old group. Furthermore, the incidence of fall in the single high-risk symptom group was $12.9 \%$ and $11.2 \%$ for the young-old and old-old, respectively; that in the double high-risk symptom group was $15.6 \%$ and $19.8 \%$, respectively; that in the triple high-risk symptom group was $35.3 \%$ and $29.1 \%$, respectively; and that in the quadruple high-risk symptom group was $71.4 \%$ and $35.7 \%$, respectively. The incidence of fall tended to increase with an increasing number of high-risk symptoms.

\subsection{Frequent High-Risk Symptoms for "Physical Function" and "Behavior and Character"}

As shown in Table 1, among the four fall risk factors in this study (physical function, disease and physical symptom, behavior and character, and environment), high-risk symptoms were frequently observed in the factors "physical function" and "behavior and character". Each factor consisted of several components. For "physical function”, these included muscular strength, lower limb strength, balancing ability, walking ability, going up and down stairs, changing and holding posture, upper limb function, and gait. For "behavior and character", these included inactivity, frequent urination, fear of falling, and risky behavior. This study also examined high-risk symptoms associated with these components in "physical function" and "behavior and character" factors.

Table 3 shows the prevalence of high-risk symptoms associated with components of the "physical function" and "behavior and character" factors calculated from the subjects with high-risk symptoms for "physical function" or "behavior and character".

Among the components of "physical function", the component with the highest percentage of subjects having a high-risk symptom was "gait" (58.6\% in the youngold and $63.6 \%$ in the old-old), and the component with the next highest percentage was "going up and down stairs" (48.9\% in the young-old and $73.5 \%$ in the oldold). The prevalence of high-risk symptoms for these components was significantly higher in the old-old, except for the prevalence of gait. Similarly, among the 
Table 2. The incidence of fall in each risk type and its difference between the young-old and old-old age groups.

\begin{tabular}{|c|c|c|c|c|c|c|c|c|c|c|}
\hline \multirow[b]{2}{*}{ Risk type } & & \multicolumn{4}{|c|}{ Fall risk factors } & \multicolumn{2}{|c|}{ Young-old age group } & \multicolumn{2}{|c|}{ Old-old age group } & \multirow[b]{2}{*}{$\begin{array}{l}\text { Chi-square } \\
\text { values }\end{array}$} \\
\hline & & $\begin{array}{l}\text { Physical } \\
\text { function }\end{array}$ & $\begin{array}{c}\text { Disease and } \\
\text { physical symptom }\end{array}$ & $\begin{array}{l}\text { Behavior } \\
\text { and character }\end{array}$ & Environment & Faller & $\%$ & Faller & $\%$ & \\
\hline $\begin{array}{l}\text { No high-risk } \\
\text { symptom group }\end{array}$ & Type 1 & $\mathrm{~N}$ & $\mathrm{~N}$ & $\mathrm{~N}$ & $\mathrm{~N}$ & 49 & 7.2 & 16 & 11.4 & 2.8 \\
\hline \multirow{4}{*}{$\begin{array}{l}\text { Only one high-risk } \\
\text { symptom groups }\end{array}$} & Type 2 & $\mathrm{P}$ & $\mathrm{N}$ & $\mathrm{N}$ & $\mathrm{N}$ & 24 & 10.6 & 27 & 11.6 & 0.1 \\
\hline & Type 3 & $\mathrm{~N}$ & $\mathrm{P}$ & $\mathrm{N}$ & $\mathrm{N}$ & 5 & 19.2 & 0 & 0.0 & 1.8 \\
\hline & Type 4 & $\mathrm{~N}$ & $\mathrm{~N}$ & $\mathrm{P}$ & $\mathrm{N}$ & 30 & 15.0 & 5 & 11.9 & 0.3 \\
\hline & Type 5 & $\mathrm{~N}$ & $\mathrm{~N}$ & $\mathrm{~N}$ & $P$ & 3 & 11.1 & 0 & 0.0 & 0.5 \\
\hline \multirow{8}{*}{$\begin{array}{l}\text { Double high-risk } \\
\text { symptoms groups }\end{array}$} & & & & & Subtotal & 62 & 12.9 & 32 & 11.2 & 0.5 \\
\hline & Type 6 & $\mathrm{P}$ & $\mathrm{P}$ & $\mathrm{N}$ & $\mathrm{N}$ & 2 & 6.3 & 9 & 19.1 & 2.6 \\
\hline & Type 7 & $\mathrm{P}$ & $\mathrm{N}$ & $P$ & $\mathrm{~N}$ & 29 & 17.9 & 38 & 20.2 & 0.3 \\
\hline & Type 8 & $\mathrm{P}$ & $\mathrm{N}$ & $\mathrm{N}$ & $\mathrm{P}$ & 1 & 5.6 & 0 & 0.0 & 0.5 \\
\hline & Type 9 & $\mathrm{~N}$ & $\mathrm{P}$ & $\mathrm{P}$ & $\mathrm{N}$ & 1 & 6.7 & 2 & 40.0 & 3.3 \\
\hline & Type 10 & $\mathrm{~N}$ & $\mathrm{P}$ & $\mathrm{N}$ & $\mathrm{P}$ & 0 & 0.0 & 0 & & \\
\hline & Type 11 & $\mathrm{~N}$ & $\mathrm{~N}$ & $P$ & $\mathrm{P}$ & 6 & 28.6 & 2 & 20.0 & 0.3 \\
\hline & & & & & Subtotal & 39 & 15.6 & 51 & 19.8 & 1.5 \\
\hline \multirow{4}{*}{$\begin{array}{l}\text { Triple high-risk } \\
\text { symptoms groups }\end{array}$} & Type 12 & $\mathrm{P}$ & $\mathrm{P}$ & $\mathrm{P}$ & $\mathrm{N}$ & 22 & 40.7 & 32 & 29.6 & 2.0 \\
\hline & Type 13 & $\mathrm{P}$ & $\mathrm{P}$ & $\mathrm{N}$ & $\mathrm{P}$ & 1 & 50.0 & 0 & 0.0 & 2.9 \\
\hline & Type 14 & $\mathrm{P}$ & $\mathrm{N}$ & $P$ & $\mathrm{P}$ & 6 & 24.0 & 5 & 38.5 & 0.9 \\
\hline & Type 15 & $\mathrm{~N}$ & $\mathrm{P}$ & $P$ & $\mathrm{P}$ & 1 & 25.0 & 0 & 0.0 & 0.3 \\
\hline \multirow{3}{*}{$\begin{array}{l}\text { Quadruple high-risk } \\
\text { symptoms group }\end{array}$} & & & & & Subtotal & 30 & 35.3 & 37 & 29.1 & 0.9 \\
\hline & Type 16 & $\mathrm{P}$ & $\mathrm{P}$ & $\mathrm{P}$ & $\mathrm{P}$ & 5 & 71.4 & 5 & 35.7 & 2.4 \\
\hline & & & & & Total & 185 & 12.3 & 141 & 17.1 & $10.0^{*}$ \\
\hline
\end{tabular}

P: positive presence of high-risk symptoms; N: negative absence of high-risk symptoms; ${ }^{*}: \mathrm{p}<0.05$.

Table 3. The prevalence of high-risk symptoms associated with components of the "physical function" and "behavior and character" factors.

\begin{tabular}{|c|c|c|c|c|c|}
\hline \multirow{3}{*}{ Components of "physical function" factor } & \multicolumn{4}{|c|}{ The elderly with high-risk symptom in "physical function” } & \multirow{3}{*}{ Chi-square values } \\
\hline & \multicolumn{2}{|c|}{ Young-old age group $(\mathrm{n}=526)$} & \multicolumn{2}{|c|}{ Old-old age group $(n=615)$} & \\
\hline & $\mathrm{n}$ & $\%$ & $\mathrm{n}$ & $\%$ & \\
\hline Gait & 308 & 58.6 & 391 & 63.6 & 3.0 \\
\hline Muscular strength & 56 & 10.6 & 172 & 28.0 & $53.2^{*}$ \\
\hline Lower limb strength & 84 & 16.0 & 253 & 41.1 & $86.3^{*}$ \\
\hline Balancing ability & 32 & 6.1 & 83 & 13.5 & $17.2^{*}$ \\
\hline Walking ability & 11 & 2.1 & 37 & 6.0 & $10.8^{*}$ \\
\hline Going up and down stairs & 257 & 48.9 & 452 & 73.5 & $73.1^{*}$ \\
\hline Changing and holding posture & 61 & 11.6 & 104 & 16.9 & $6.5^{*}$ \\
\hline \multirow[t]{2}{*}{ Upper limb function } & 125 & 23.8 & 283 & 46.0 & $61.1^{*}$ \\
\hline & \multicolumn{4}{|c|}{ The elderly with high-risk symptom in physical function $(\mathrm{n}=526)$} & \\
\hline \multirow{2}{*}{ Components of "behavior and character" factor } & \multicolumn{2}{|c|}{ Young-old age group $(\mathrm{n}=488)$} & \multicolumn{2}{|c|}{ Old-old age group $(\mathrm{n}=381)$} & Chi-ssuare values \\
\hline & $\mathrm{n}$ & $\%$ & $\mathrm{n}$ & $\%$ & - \\
\hline Inactivity & 42 & 8.6 & 72 & 18.9 & $19.9^{*}$ \\
\hline Frequent urination & 98 & 20.1 & 52 & 13.6 & $6.2^{*}$ \\
\hline Fear of falling & 400 & 82.0 & 353 & 92.7 & $21.1^{*}$ \\
\hline Risky behavior & 94 & 19.3 & 29 & 7.6 & $23.9^{*}$ \\
\hline
\end{tabular}

${ }^{*}: \mathrm{p}<0.05$ 
components of "behavior and character," the prevalence of high-risk symptoms for "fear of falling" was very high (82.0\% in the young-old and $92.7 \%$ in the old-old). The prevalence of all the components was significantly higher in the old-old age group.

\section{DISCUSSION}

One of most important health promotions necessary to achieve successful aging of the elderly living independently in the community is to prevent becoming in a condition of need for long-term care. In Japan, which has a declining birth rate, an aging society, and an extending healthy life expectancy (reaching approximately 75 years), the population pyramid has begun to change and is expected to be upside-down in near future [16]. Therefore, it is an important social and national issue to build countermeasures for ensuring successful aging of the old-old population. Fall is a major obstruction to successful aging, and its primary prevention is very important. Determination of fall risk characteristics of the old-old population is useful to establish measures for primary prevention of falling.

Our previous study, examining fall risk types based on 1000 or more community-dwelling elderly people, reported that three groups of the elderly population, namely those with no high-risk symptoms, those with one highrisk symptom, and those with two or more high-risk symptoms, represented approximately $30 \%$ of the study population [13]. However, in that study, how fall risk characteristics varied from the young-old to old-old population remained unclear.

This study compared the fall risk characteristics of more than 2000 elderly people who were divided into young-old and old-old age groups and clarified several findings that differ from the findings of our previous study. Thus, the percentage of subjects in the no highrisk symptom group was $45 \%$ in the young-old group; however, it was $17 \%$ in the old-old group. Although the percentage of subjects with a single high-risk symptom remained unchanged from the young-old to the old-old groups, the percentage of subjects with two or more high-risk symptoms reached to nearly $50 \%$ of the old-old elderly people (48\%). These differences are interesting and meaningful.

In performance test-based fall risk assessment, it is often difficult to obtain a large sample size of old-old people. In this study, although there is a limitation based on questionnaire-based fall risk assessment, our findings were obtained from a large sample size of 2000 or more elderly people, with which we could provide meaningful information to clarify the fall risk characteristics of the community-dwelling elderly and their age-specific changes from the young-old to old-old.
This study determined that a high prevalence of highrisk symptoms was observed in the "physical function" and "behavior and character" and further examined their components with a high prevalence rate. The symptoms for "physical function" with a high prevalence of highrisk persons in the young-old were gait (58.6\%) and going up and down stairs (48.9\%). Considering the low prevalence of muscular strength (10.6\%), lower limb muscular strength $(16.0 \%)$, balancing ability (6.1\%), and walking ability (2.1\%), over half of the young-old population has a worsening of gait (such as increases in trips or stumbles); however, they have the mobility and other physical functions necessary for independent living. Then, in the old-old population, the worsening of gait is associated with a decline in lower limb function, as our observations of the prevalence of high-risk in lower limb muscular strength $(41.1 \%)$, going up and down stairs (73.5\%), and balancing ability (13.5\%) demonstrate. In the old-old population, the prevalence of disease in locomotive organs also increases [17]. Considering these characteristics of fall risk or diseases of the old-old population, fall risk assessment and preventive intervenetion are necessary. Furthermore, the symptom for "behavior and character", which showed the highest prevalence of high-risk persons, was fear of falling $(82.0 \%$ in the young-old; $92.7 \%$ in the old-old). This suggests that many elderly people have the fear of falling regardless of their level of physical function or age. It will be beneficial for the elderly to pay attention to falling; however, excessive fear of falling promotes the decline of physical function because of inactivity. Therefore, starting at a young-old age, when people have sufficient physical function for independent living, education is necessary to reduce inactivity that arises from the fear of falling and interventions are necessary to maintain the amount of physical activity.

The incidence of fall in the elderly with high-risk symptoms did not change in the old-old population, although the incidence of fall in those with no high-risk symptom was significantly higher in the old-old population $(7.2 \%$ vs $11.4 \%)$. However, the prevention of fall in the old-old population continues to be a key problem in the aging society because of the facts that the incidence of fall increased with an increase in the number of high-risk symptoms, that the prevalence of the elderly with single or multiple high-risk symptoms increased in the old-old, and that the size of the old-old population is expected to increase in future.

This study derived 16 risk profiles (risk types) from dichotomising each risk factor automatically, and descriptively examined the prevalence of each risk profile and its incidence of fall. These descriptive procedures could provide several interest findings. In contrast, considering the fact that these fall risk factors are not 
independently, analyzes controlling mutual effect among these factors may be ideal for ascertaining practical (actual/realistic) risk profiles (groups). Therefore, the risk profiles (groups) and risk characteristics obtained from the descriptive procedures have limitations to the generalization. Further examinations using multivariate analyses may be required.

\section{CONCLUSION}

In the old-old, the percentage of the elderly with no high-risk symptom decreased to $17.0 \%$ and that of the elderly with two or more high-risk symptoms reached to nearly 50\%. Furthermore, high prevalence of high-risk symptoms was observed in the risk factors "physical function" and "behavior and character", particularly in the symptoms of gait, going up and down stairs, and fear of falling. The prevalence increased in the old-old. The incidence of fall in the elderly with high-risk symptoms did not change with age, although the incidence of fall in the elderly with no high-risk symptom increased in the old-old.

\section{ACKNOWLEDGEMENTS}

We are very grateful to the subjects for their enthusiastic participation during our measurements. The study was supported by the Japan Society for the Promotion of Science (Grant-in-Aid for Scientific Research (A) \#21240064). The authors would like to thank Enago (www.enago.jp) for the English language review.

\section{REFERENCES}

[1] Health, Labour and Welfare Statistics Association (2012) Annual statistical reports of national health conditions 2010/2011.

[2] Health, Labour and Welfare Ministry (2012) The 21st life tables, complete life table. www.mhlw.go.jp/english/database/db-hw/lifetb21th/index.html

[3] World Health Organization (2011) World health statistics 2010.

[4] Nakamura, K. (2009) Locomotive syndrome: Disabilityfree life expectancy and locomotive organ health in a "super-aged" society. Journal of Orthopaedic Science, 14, 1-2. doi:10.1007/s00776-008-1302-y

[5] Nakamura, K. (2011) The concept and treatment of locomotive syndrome: Its acceptance and spread in Japan. Journal of Orthopaedic Science, 16, 489-491. doi:10.1007/s00776-011-0108-5

[6] Gates, S., Smith, L.A., Fisher, J.D., et al. (2008) Systematic review of accuracy of screening instruments for predicting fall risk among independently living older adults.
Journal of Rehabilitation Research and Development, 45, 1105-1116. doi:10.1682/JRRD.2008.04.0057

[7] Gnz, D.A., Higashi, T. and Rubenstein, L.Z. (2005) Monitoring falls in cohort studies of community-dwelling older people: Effect of the recall interval. Journal of the American Geriatrics Society, 53, 2190-2194. doi:10.1111/j.1532-5415.2005.00509.x

[8] Lord, S.R., Tiedemann, A., Chapman, G.K., et al. (2005) The effect of an individualized fall prevention program on fall risk and falls in older people: A randomized, controlled trial. Journal of the American Geriatrics Society, 53, 1296-1304. doi:10.1111/j.1532-5415.2005.53425.X

[9] Liu-Ambrose, T.Y.L., Khan, K.M., Eng, J.J., et al. (2005) The beneficial effects of group-based exercises on fall risk profile and physical activity persist 1 year post intervention in older women with low bone mass: Follow-up after withdrawal of exercise. Journal of the American Geriatrics Society, 53, 1767-1773. doi:10.1111/j.1532-5415.2005.53525.x

[10] Gregg, E.W., Pereira, M.A. and Caspersen, C.J. (2000) Physical activity, falls, and fractures among older adults: A review of the epidemiologic evidence. Journal of the American Geriatrics Society, 48, 883-893.

[11] Tinetti, M.E., Speechley, M. and Ginter, S.F. (1988) Risk factors for falls among elderly persons living in the community. The New England Journal of Medicine, 319, 17011707. doi:10.1056/NEJM198812293192604

[12] Sato, S., Demura, S., Shin, S., et al. (2012) Assessing a personal and population fall risk profile in Japanese community-dwelling elderly. Japan Journal of Test and Evaluation of Physical Education and Sports, 12, 49-55. (in Japanese)

[13] Demura, S., Sato, S., Shin, S., et al. (2012) Fall risk types and the fall prevalence rates of Japanese communitydwelling elderly. Gazzetta Medica Italiana, in Press.

[14] Demura, S., Sato, S., Yokoya, T., et al. (2010) Examination of useful items for the assessment of fall risk in the community-dwelling elderly Japanese population. Environmental Health and Preventive Medicine, 15, 169-179. doi:10.1007/s12199-009-0124-7

[15] Demura, S., Kasuga, K., Sato, S., et al. (2013) Determination of persons at a high risk of falling in a population of healthy community-dwelling elderly Japanese. International Journal of Gerontology, 7, 13-16. doi:10.1016/j.ijge.2012.05.007

[16] Ministry of Internal Affairs and Communications (2012) Statistics bureau, population estimates. http://www.stat.go.jp/info/guide/asu/2012/02.htm

[17] Yoshimura, N., Muraki, S., Oka, H., et al. (2009) Prevalence of knee osteoarthritis, lumbar spondylosis, and osteoporosis in Japanese men and women: The research on osteoarthritis/osteoporosis against disability study. Journal of Bone and Mineral Metabolism, 27, 620-628. doi:10.1007/s00774-009-0080-8 